\title{
Sulu Çözeltilerden Fosfor Gideriminde Demir ile Kaplanmış Aktif Karbonun Kullanılabilirliğinin Araştırılması
}

\author{
Hasan Kıvanç YEŞILTAŞ̧⿻ ${ }^{1}$, Turan YILMAZ ${ }^{* 1}$ \\ ${ }^{1}$ Çukurova Üniversitesi, Mühendislik Fakültesi, Çevre Mühendisliği Bölümü, Adana
}

Geliş tarihi: 13.07.2019 Kabul tarihi: 20.12 .2019

\section{$\ddot{O} z$}

Fosfor canlılar için temel bir nütrient olmasının yanı sıra sucul ortamlarda çok düşük konsantrasyonlarda ötröfikasyon adı verilen çevresel bir probleme sebep olmaktadır. Bu araştırmada ticari olarak satışı olan aktif karbon malzemesi demir ile kaplanarak sentezlenen yeni malzeme (DKK) ile fosfor giderimi araştırılmıştır. Yapılan laboratuvar çalışmaları sonucunda DKK'nın sulu çözeltilerde fosfor gideriminde işlevsel olarak kullanılabileceği anlaşılmıştır. Ayrıca malzemenin fosfor tutma kapasitesinin 4,26 mg $\mathrm{PO}_{4}{ }^{3-} / \mathrm{g}$ DKK olduğu tespit edilmiştir. Adsorpsiyonun Langmuir matematiksel modeline uyduğu ve üretim için uygun şartların sağlanması ile birlikte ticari olarak üretiminin gerçekleştirilerek fosfor gideriminde yaygın olarak kullanılabileceği sonucuna varılmıştır.

Anahtar Kelimeler: Fosfor giderimi, Aktif karbon, Adsorpsiyon izotermleri, Karbon kaplama

\section{Investigation of Usability of Iron Coated Activated Carbon for Phosphorus Removal from Aqueous Solutions}

\begin{abstract}
Phosphorus is a basis nutrient for living organisms, but also causes an environmental problem called eutrophication at very low concentrations in aquatic environments. In this research, the commercially available activated carbon material was coating with iron and phosphorus removal was investigated with synthesized new material (DKK). As a result of laboratory studies, it was found that DKK can be used functionally in phosphorus removal in aqueous solutions. In addition, the phosphorus holding capacity of the material was found to be $4.26 \mathrm{mg} \mathrm{PO}_{4}{ }^{3-} / \mathrm{g}$ DKK. It has been concluded that adsorption complies with the Langmuir mathematical model and can be used in phosphorus removal by commercially synthesizing with appropriate conditions for production.
\end{abstract}

Keywords: Phosphorus removal, Activated carbon, Adsorption 1sotherms, Carbon coating

\footnotetext{
*Sorumlu yazar (Corresponding author): Turan YILMAZ, tyilmaz@cu.edu.tr
} 


\section{GíRiş}

Fosfor, yaşam için vazgeçilmez bir element olma özelliğine sahiptir [1]. Canlıların hücre yapısında, aminoasitlerin ve proteinlerin yapısında bulunduğu gibi elektron taşıma sisteminde aktif olarak görev yapmaktadır [1-3]. Fotosentez için anahtar element görevi gören fosfor aynı zamanda hem zirai hem de endüstriyel faaliyetlerde yaygin olarak kullanılmaktadır [1,4]. Dünya'daki fosfor rezervleri sınırlı olup [5] nüfus artışı ile birlikte üretime paralel olarak fosfor ihtiyacı günden güne artmakta olup günümüzde geri kazanımı ve yeniden kullanılması önemli hale gelmiştir.

Fosfor içeren atıksular alıcı ortama deşarj edilmeleri ile birlikte sucul canlılar tarafindan besin olarak tüketilmektedir. $\mathrm{Bu}$ tüketimin sonucunda sucul canlıların aşırı çoğalmakta ve ötröfikasyon adı verilen çevresel probleme sebep olmaktadırlar [6-8]. Sucul ortamlarda meydana gelen bu istenmeyen durum neticesinde estetik olarak uygun olmayan bir görüntü, koku oluşumu, sistemdeki oksijen miktarında azalma, canlı ölümleri ve ekolojik olarak sistemin dengesinde bozulmalar meydana gelebilmektedir [6-10].

$\mathrm{Su}$ ve atıksulardan fosfor gideriminde çeşitli yöntemler mevcuttur. Fosfor giderim metotlarının seçiminde temel olarak atıksuyun karakteristiği, deşarj standartları, kurulacak alanın halihazır durumu, yatırım ve işletme maliyeti etkili olmaktadır. Biyolojik metotlar arasında aktif çamur daha yerleşmiş durumdadır [11]. Fakat bu metot ile çamur oluşumu gerçekleşmekte ve düşük konsantrasyonlarda fosfor giderimi yapılması pek mümkün olmamaktadır $[11,12]$. Çeşitli kimyasal metotları arasında adsorpsiyon ve iyon değiştirme prosesleri yaygın olarak kullanılmakta olup daha az alana gereksinimi, çamur oluşturmaması ve işletme kolaylığı açısından biyolojik metotlara göre avantajlı olmaktadır $[4,9,13]$. Bu yöntemler ile ayrıca düşük konsantrasyonlarda fosfor giderimi gerçekleştirilebilirken [12] kullanılan materyale ve yönteme göre fosfor geri kazanımı da gerçekleştirilebilmektedir.

Adsorpsiyon metodunda yaygın olarak alüminyum oksit, demir oksit, zirkonyum oksit, çift tabakalı hidroksitler, zeolit, uçucu kül, yüksek firın cürufu, kömürleştirme ile hazırlanmış adsorbantlar gibi doğal ya da yapay malzemeler kullanılmaktadır [4,11-14]. Kömürleştirme ile elde edilmiş olan malzemelerden yaygın olarak çeşitli kirleticilerin giderimleri ile çalışmalar yapılmıştır $[13,15]$.

Aktif karbon kirletici gideriminde çeşitli alanlarda kullanımı mevcut olan ekonomik ve kullanışlı bir malzemedir. Ticari olarak satılan aktif karbonlar üretim tekniğinden kaynaklı olarak gözenekli ve geniş yüzey alanına sahiptir. Adsorpsiyon işleminde kullanılacak adsorbantın ise öncelikli olarak yüzey alanının fazla olması ve poröz bir yapıya sahip olması tercih edilmektedir. Doğal sularda ve atıksularda bulunan nitrat, fosfat, klorür, bromit ve iyot gibi anyonların aktif karbona adsorbe olma özellikleri zayıf olmaktadır [16]. Bu sebepten dolayı giderilmek istenilen parametreye göre kullanılacak malzemenin adsorpsiyon kapasitesinin uygun metotlar ile arttırılarak fosfor gideriminin daha verimli gerçekleştirilebileceği düşünülmektedir. Bu çalışmada sentezlenmiş olan DKK'nın fosfor giderim verimliliği, su ve atıksularda kullanılabilirliği ve fosfor tutma kapasitesi incelenmiştir.

\section{MATERYAL VE METOT}

\subsection{Materyal}

\subsubsection{Sentetik Fosfor Çözeltisi}

$\mathrm{Bu}$ çalışmada dihidrojen fosfat $\left(\mathrm{KH}_{2} \mathrm{PO}_{4}\right)$ tuzundan hazırlanmış olan fosfor çözeltisi kullanılmıştır. Hazırlanmış olan çözeltide orto-fosfat analizi gerçekleştirilmiştir.

\subsubsection{Kullanılan Cihazlar ve Reaktifler}

Orto-fosfat ölçümleri Perkin Elmer TU-1880 UVSpektrofotometre kullanılarak ölçülmüştür. Ayrıca sentezlenen numuneleri kurutma için Nüve FN500 etüv, fosfor giderim çalışmalarında kullanılmak üzere Optic Ivyman marka çalkalayıcı ve sentez esnasında kullanılmak üzere Wisd WiseStir MSH20A manyetik karıştırıcı ve potasyum dihidrojen fosfat (Merck, \%98-100, $\mathrm{KH}_{2} \mathrm{PO}_{4}$ ), demir(III) klorür (Sigma, \%98'lik, $\mathrm{FeCl}_{3} \cdot 6 \mathrm{H}_{2} \mathrm{O}$ ), sülfürik asit 
(Tekkim, \%95-98, $\mathrm{H}_{2} \mathrm{SO}_{4}$ ) ve nitrit asit (İsolab, $\% 65, \mathrm{HNO}_{3}$ ) reaktifleri kullanılmıştır.

\subsubsection{Aktif Karbon}

$\mathrm{Bu}$ çalışmada fosfor giderimi için sentezlenerek kullanılacak olan demir kaplamalı aktif karbon (DKK) için Merck marka granüler aktif karbon tercih edilmiştir. İlgili markadan temin edilen aktif karbon 1,5 mm tane çapına sahip olup katalog numarası ise 102514 olmaktadır.

\subsection{Metot}

\subsubsection{Demir ile Kaplanmış Aktif Karbon Sentezi}

Sentez iki aşamadan oluşmaktadır. İlk aşama aktif karbonun oksidasyonu ile safsızlığın giderilmesi ve porozitenin arttırılması aşaması olup ikinci aşama ise demir ile kaplama aşamasıdır.

Senteze başlarken önceden çeker ocak içerisinde hazırlanmış olan 1:1 oranındaki nitrik asit ve sülfürik asit çözeltisine yavaş yavaş aktif karbon eklenerek manyetik karıştırıcı vasıtasıyla 30 dakika süresince karıştırma işlemi uygulanır. 30 dakikalık sürecin sonunda ilk adım olan oksidasyon işlemi tamamlanır. Süzülerek alınan malzemenin saf su ile yıkama işlemi gerçekleştirilerek kuruması için 60 dakika süresince etüvde $105^{\circ} \mathrm{C}$ sicaklıkta bekletilir.

İkinci aşamada ise $\mathrm{FeCI}_{3}$ tuzundan hazırlanan 0,5 M demir çözeltisine kurutulmuş olan aktif karbon eklenerek 60 dakika bekletilir. Devamında süzülerek $105^{\circ} \mathrm{C}$ 'de 60 dakika kurutulur. Kurutma işleminin devamında ise saf su ile birkaç kez yıkanarak tekrar 60 dakika kurutma işlemine tabi tutulur. Kurutma işlemi takiben DKK'nin sentez aşaması tamamlanmıştır.

\subsubsection{Analitik Metotlar}

Fosfor analizleri Standart Methods [17], 4500-P C analiz yöntemine göre Perkin Elmer TU-1880 model UV-VIS spektrofotometre ile gerçekleştirilmiştir. Cihaza ait kalibrasyon grafiği
Şekil 1'de ve kalibrasyon denklemi ise $\left(\mathrm{R}^{2}=0,9957\right)$ Eşitlik 1'de yer almaktadır.

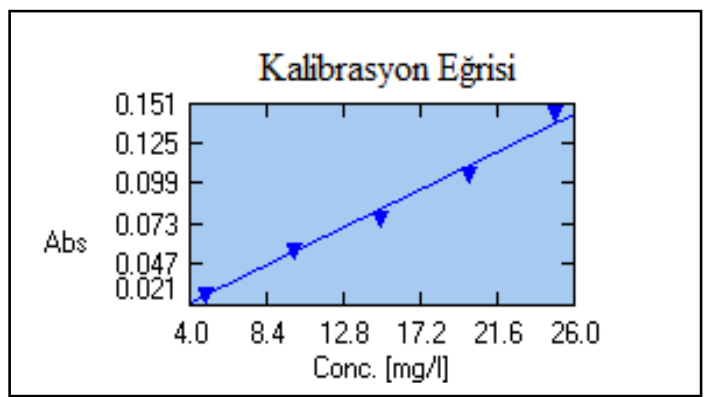

Şekil 1. Cihaza ait kalibrasyon eğrisi (conc: konsantrasyon, abs: absorbans)

$\mathrm{Abs}=0,00559 \times(\mathrm{Conc})-0,00194$

\subsubsection{Demir ile Kaplanmış Aktif Karbon Kullanarak Fosfor Giderimi}

Potasyum dihidrojen fosfat tuzundan hazırlanmış olan $20 \mathrm{mg} \mathrm{PO}_{4}{ }^{3-} / \mathrm{L}$ konsantrasyona sahip stok çözelti kullanılarak fosfor giderimi incelenmiştir. Sentezi gerçekleştirilerek kullanıma hazır hale getirilen DKK'dan $5 \mathrm{~g}$ tartilarak 250 mL'lik reaktöre konulmuştur. Devamında $100 \mathrm{~mL}$ stok fosfat çözeltisinden alınarak reaktöre konulmuş ve 10 dakika süresince çalkalayıcı yardımıyla tam karışımlı ortamda fosfor giderimi incelenmiştir. 10 dakikalık temas süresinin devamında çözelti selüloz asetat filtre (gözenek çap1, 0,45 $\mu \mathrm{m}$ ) ile filtrasyon işlemine tabi tutularak orto-fosfat analizi yapılmıştır.

\subsubsection{Demir ile Kaplanmış Aktif Karbon Kullanarak Fosfor Tutma Kapasitesinin Belirlenmesi}

$500 \mathrm{~mL}$ hacimli reaktöre $10 \mathrm{~g}$ DKK tartılarak

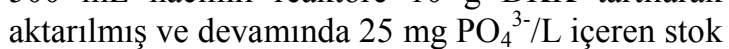
çözeltiden $200 \mathrm{~mL}$ eklenmiştir. Tutma kapasitesinin belirlenmesi için 10 dakika temas süresi boyunca çalkalama işlemine tabi tutulmuştur. 10 dakikalık süre sonunda çalkalama işlemi durdurulmuş ve reaktördeki çözelti bir behere aktarılarak orto-fosfat analizi için hazır hale getirilmiştir. DKK bulunan reaktöre yeniden stok fosfat çözeltisinden $200 \mathrm{~mL}$ fosfat çözelti 
aktarılmış ve işlem tekrarlanmıștır. Bu işlem tekrarlanarak malzemenin fosfor tutma kapasitesi belirlenmiştir.

\subsubsection{Adsorpsiyon Denge İzotermleri}

Sabit sicaklıkta birim adsorban kütlesi ve adsorplanan madde miktarı arasındaki ilişkiyi açıklayan ampirik eşitliklere adsorpsiyon denge izotermleri denir [18]. Kesikli deneysel çalışmalardan elde edilen veriler yaygın olarak Freundlich, Langmuir (Tip 1-4), Temkin, DubininRadushkevich, Koble-Corrigan, Redlich-Peterson ve Fritz-Schlünder gibi izoterm modellerine uygulanır. Bu çalışmada 5 farklı DKK kütlesi $(2,4,6,8$ ve $10 \mathrm{~g})$ belirlenerek fosfor giderimi çalışılmış ve analiz verileri dört (Freundlich, Langmuir, Temkin ve Dubinin-Radushkevich) farklı matematiksel izoterm modeline uygulanmıştır.

\section{BULGULAR VE TARTIŞMA}

\subsection{Aktif Karbon ve DKK Sentezi}

Üretim mekanizmasından kaynaklı olarak yüzey alanı geniş olan aktif karbonun senteze başlamadan önce bünyesinde bulundurmuş olduğu safsızlıklardan uzaklaştırılması önem taşımaktadır. $\mathrm{Bu}$ amaç ile bu araştırmada Nitrik asit ve sülfürik asit, 1:1 oranında kullanılmış olup aynı zamanda malzemenin porozitesinin de arttırılması hedeflenmiştir. $\mathrm{Bu}$ oran ve asitler değiştirilerek malzemenin tekrar sentezlenmesi ile malzemenin giderim kapasitesinin geliştirilmesi ileriki çalışmalarda amaçlanabilir. Aktif karbonun yüzeyinde yer alabilecek safsızlıkların uzaklaştırılması ile birlikte hali hazırda çeşitli giderim proseslerinde kullanılan aktif karbonun bu çalışmanın işlevine uygun olarak kullanılması gerçekleştirilebilir fakat doğal olarak suda mevcut fosfata $\left(\mathrm{PO}_{4}{ }^{3-}\right)$ ilgisi az olan (Çizelge 1) aktif karbonun modifikasyonu ile amacina uygun kullanımı gerçekleştirilebilir. Bu çalışmada aktif karbon demir ile kaplanmış olup sentezlenen yeni malzemenin fosfor giderimindeki etkisi araştırılmıştır.
Çizelge 1. Sulu çözeltide bulunan anyonların adsorpsiyon potansiyeli [16]

\begin{tabular}{|c|c|}
\hline Anyon & Adsorpsiyon Potansiyeli \\
\hline $\mathrm{NO}_{3}^{-}$ & Düşük \\
\hline $\mathrm{PO}_{4}^{-3}$ & Düşük \\
\hline $\mathrm{Cl}^{-}$ & Düşük \\
\hline $\mathrm{Br}^{-}$ & Düşük \\
\hline $\mathrm{I}^{-}$ & Düşük \\
\hline $\mathrm{F}^{-}$ & Yüksek \\
\hline
\end{tabular}

\subsection{DKK ile Fosfor Giderimi}

$\mathrm{Bu}$ çalışmada sentezlenmiş olan DKK ile oda sıcaklığında $\left(\cong 24^{\circ} \mathrm{C}\right)$ yapılmış olan fosfor giderimi çalışması Başlık 2.2.3'de yer alan metoda uygun olarak gerçekleştirilmiştir. Çalışmanın bu adımında \%95,2 fosfor giderim verimi elde edilmiştir. $\mathrm{Bu}$ değer her ne kadar yüksek görünse de fosfat gideriminde kullanılan malzeme miktarı ve başlangıç fosfat miktarı gibi temel iki değişkene göre bile değişebilecek bir hesaplamadır. Kpannieu ve arkadaşları [9], bünyesinde demirce zengin doğal kumtaşı, alüminyum içeriği zengin laterit ve şist ile yapmış oldukları fosfat giderim çalışmasında kumtaşı ve laterit ile \%100'lük fosfor giderme verimi elde ederken şist ile bu orana ulaşamadıklarını bildirmişlerdir.

Fosfor gideriminde kullanılan malzemenin miktarının artması ile giderimin artacağı bilinmektedir. Verim verisinin malzemenin kullanılabilirliği açısından tek başına yeterli olmaması sebebiyle kullanılan malzeme miktarları arttırılarak çalışma sürdürülmüştür. Reaktördeki DKK kütlesinin artırılması ile yapılan çalışma sonucunda Şekil 2 elde edilmiştir.

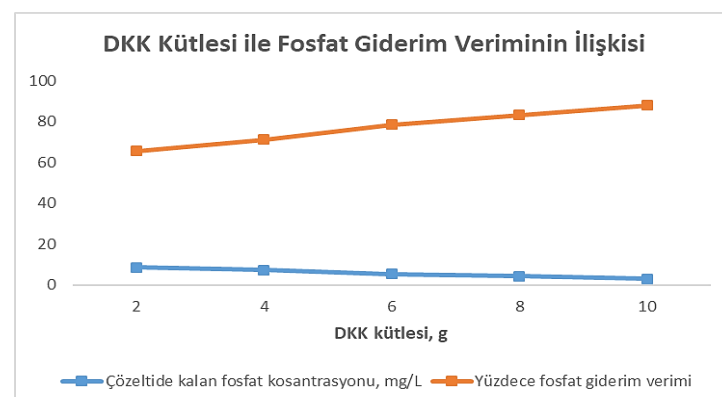

Şekil 2. DKK kütlesinin çözeltide kalan fosfat miktarı ve yüzdece fosfat giderimine etkisi 
DKK kullanımının 2 g ve 10 g olması durumunda reaktör çıkışındaki orto-fosfat değerleri (yüzdece fosfor giderim değerleri) sirası ile $8,6 \mathrm{mg} \mathrm{PO}_{4}{ }^{3-} / \mathrm{L}$ $(\% 65,6)$ ve $3 \mathrm{mg} \mathrm{PO}_{4}^{3-} / \mathrm{L} \quad(\% 88)$ olmaktadir. Şekil 2'de görüldüğü gibi reaktörde kullanılan DKK kütlesinin artışı ile tutulan fosfor miktarının arttığı ve bu değişimin fosfor giderim verimini olumlu yönde etkilediği tespit edilmiştir. Yeşiltaş ve arkadaşları [14], $\mathrm{FeCI}_{3}$ ve $\mathrm{MgCI}_{2}$ tuzlarından sentezlemiş oldukları $\mathrm{Mg}-\mathrm{Fe}$ çift katmanlı hidroksitleri yaptıkları fosfor giderim çalışmasında 125-180 $\mu \mathrm{m}$ partikül çapı sınıfına ait ÇKH'dan $0,1 \mathrm{~g}$ ve $0,5 \mathrm{~g}$ kullanmış ve çözeltide kalan ortofosfat konsantrasyonlarını (yüzdece fosfor giderim değerlerini) sırası ile $15,91 \mathrm{mg} \mathrm{PO}_{4}{ }^{3-} / \mathrm{L}(\% 25)$ ve $3,39 \mathrm{mg} \mathrm{PO}_{4}{ }^{3-} / \mathrm{L}(\% 84)$ olarak tespit etmişlerdir.

\subsection{DKK'nın Fosfor Tutma Kapasitesinin Tespiti}

Sentezlenmiş olan malzemenin fosfor tutma kapasitesinin belirlenmesi diğer malzemeler ile karşılaştırılması ve sentezlenen malzemeler arasındaki yerinin belirlenmesi için önem taşımaktadır. Başlık 2.2.4'de verilen yönteme bağlı olarak DKK'nın fosfor tutma kapasitesi çalışılmış olup kapasitesi 4,26 mg $\mathrm{PO}_{4}^{-3} / \mathrm{g}$ DKK (1,39 mg P/g DKK) olarak tespit edilmiştir. Barca ve arkadaşları [19], elektrikli ark ocağı cürufu (EAF-slags) ve bazik oksijen ocağ 1 cürufu (BOK-slags) ile yaptıkları fosfor giderim çalışmasında sırası ile 0,09-0,28 mg P/g ve 0,03-2,49 mg P/g aralığında fosfor tutma kapasitesine ulaştıklarını bildirmişlerdir. Zhang ve arkadaşları [13], belediyeye ait atıksu arıtma tesisinden temin ettikleri çamurdan sentezlemiş oldukları CSA, CSA-D-1 ve CSA-D-2 olarak kisaltilan malzemeleri ile sirasi ile 2,99 $\mathrm{mg} \mathrm{PO}_{4}^{-3} / \mathrm{g}, 1,48 \mathrm{mg}$ $\mathrm{PO}_{4}{ }^{3-} / \mathrm{g}$ ve $1,05 \mathrm{mg} \mathrm{PO}_{4}{ }^{3-} / \mathrm{g}$ fosfor tutma kapasitesi, Yeşiltaş ve arkadaşları [14], sentezlemiş oldukları $\mathrm{Mg}-\mathrm{Fe}$ ve Mg-Al ÇKH'ları ile en küçük partikül sınıflarını kullanarak, yaptıkları çalışmada malzemelerin fosfor tutma kapasitelerini sirası ile $3 \mathrm{mg} \mathrm{PO}_{4}{ }^{3-} / \mathrm{g}$ ve $57,5 \mathrm{mg} \mathrm{PO}_{4}{ }^{3-} / \mathrm{g}$ olarak tespit ettiklerini bildirmişlerdir. Değerler incelendiği zaman DKK'nın çeşitli materyallere göre fosfor tutma kapasitesinin avantajlı olduğu görülmektedir. Hali hazırda yapılan çalışmalar ile fosfor tutma kapasitesinin artırılabileceği düşünülmekte olup çeşitli kolon prosesleri için kullanılabilir olduğu yapılan bu araştırma esnasında fark edilmiştir.

\subsection{Temas Süresinin Fosfor Giderimine Etkisi}

DKK'nın fosfor tutma kapasitesi araştırılırken ayrıca temas süresinin etkisi de incelenmiştir. Kapasite tayini yapılırken DKK için temas süresi reaktörde 10 dakika olarak seçilmiştir. Fakat çalışma esnasında 15 setin ikisinde bekleme süresi olarak 8 saat seçilmiş olup bekletme süresinin fosfor giderimine etkisi de gözlenmiştir. Temas süresinin fosfat giderimine etkisi Şekil 3'de yer almaktadir.

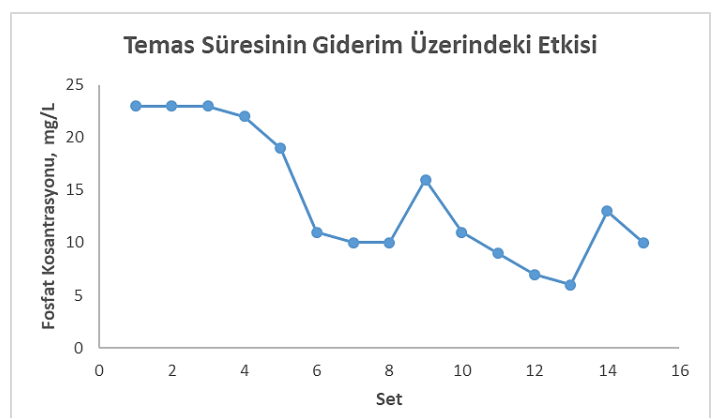

Şekil 3. Temas süresinin fosfor giderimine etkisi

Şekil 3'de yapılmış olan çalışmanın 9. ve 14 . setlerde orto-fosfat analizleri neticesinde bekletme süresinin artışının fosfor giderimine olumlu etkisinin olduğu görülmektedir. Krishna ve arkadaşları [20], kalsine edilmiş kireç çamuru ile yapmış oldukları fosfor giderim çalışmasında 5 dakika süren temas süresi için $\% 96$ fosfor giderim verimi elde etmişlerdir, temas süresinin 30 dakikaya arttırılması ile ise $\% 99$ fosfor giderim verimi değerine ulaşmışlardır.

\subsection{Adsorpsiyon İzotermleri}

DKK kütleleri (Başlık 2.2.5) değiştirilerek yapılmış olan fosfor giderimi çalışmasında, kullanılan DKK kütleleri ile birlikte çözeltide kalan orto-fosfat değerleri Freundlich, Langmuir (Tip 1-4), Temkin ve Dubinin-Radushkevich izoterm modellerinde veri olarak kullanılmıştır. Adsorpsiyon izoterm modellerinden elde edilen 
çıktılar incelendikten sonra yapılan çalışmanın Langmuir Tip 2 izotermine daha uygun olduğu $\left(\mathrm{R}^{2}=0,907\right)$ tespit edilmiştir (Şekil 4).

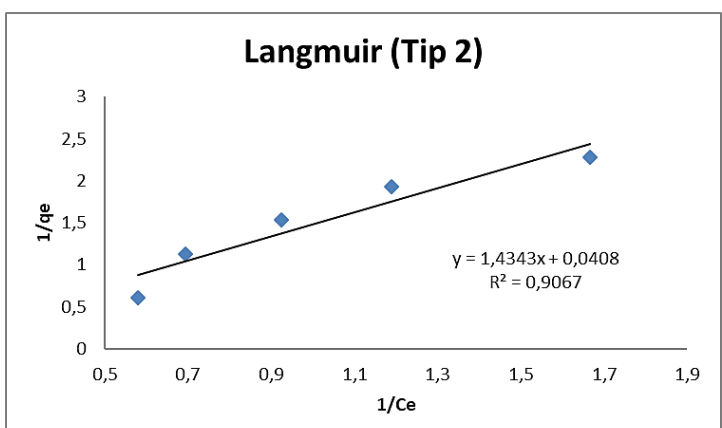

Şekil 4. İzoterm parametreleri kullanılarak oluşturulmuş olan Langmuir Tip 2 grafiği

Langmuir izotermi aynı enerji seviyelerine sahip belirli bir sayıda homojen girilebilir bölge olduğu kabulüne dayanan tek tabakalı bir izoterm modelidir. Adsorpsiyon izotermlerinin ampirik formülü Eşitlik 2'de çeşitli araştırmacılar tarafından geliştirilerek çeşitli şekillerde ifade edilmektedir. $\mathrm{Bu}$ çalışmada incelenen Langmuir izotermi matematiksel modelleri arasindan Tip 2'ye ait matematiksel model Eşitlik 3'de yer almaktadır. Ayrıca Langmuir izotermi için temel bir öneme sahip olan ayırma faktörü $R_{L}$ değerlerinin hesabı için kullanılan matematiksel eşitlik ise Eşitlik 4'te yer almaktadır.

$$
\begin{aligned}
& q_{e}=\frac{x}{m}=\frac{C_{0}-C_{e}}{m} \\
& 1 / q_{e}=\left(1 / K_{L} q_{m} C_{e}\right)+\left(1 / q_{m}\right) \\
& R_{L}=1 /\left(1+K_{L} C_{0}\right)
\end{aligned}
$$

Eşitlik 2-4'de; $\mathrm{q}_{\mathrm{e}}=$ Dengede birim adsorban kütlesi başına adsorblanan maddenin kütlesini $(\mathrm{x} / \mathrm{m}), \mathrm{m}=$ kullanılan adsorban kütlesini, $\mathrm{C}_{0}=$ başlangıçtaki madde konsantrasyonunu, $\mathrm{C}_{\mathrm{e}}=$ adsorbsiyondan sonra çözeltide kalan madde konsantrasyonunu, $\mathrm{q}_{\mathrm{m}}=$ Tek tabaka sorpsiyon kapasitesini, $\mathrm{K}_{\mathrm{L}}=$ Langmuir izoterm sabitini, $\mathrm{R}_{\mathrm{L}}=$ adsorpsiyonun geri dönüşümlü ya da geri dönüşümsüz olduğunu belirlemede kullanılan göstergeyi ifade etmektedir. $\mathrm{R}_{\mathrm{L}}$ değeri 0 olmas1 durumunda adsorpsiyonun geri dönüşümsüz olduğu kabul edilir, değerin 0 ile 1 arasında olması istenmektedir. $\mathrm{R}_{\mathrm{L}}$ değeri 1'den büyük olması durumu ise tercih edilmemektedir. Langmuir Tip 2 adsorpsiyon izotermine ait elde edilen ve hesaplanan değerler Çizelge 2'de yer almaktadır.

Çizelge 2. Langmuir Tip 2 izoterm modeli kullanılarak hesaplanan katsayılar

\begin{tabular}{|l|c|}
\hline Parametre & Değer \\
\hline $\mathrm{q}_{\mathrm{m}}, \mathrm{mg} / \mathrm{g}$ & 24,51 \\
\hline $\mathrm{K}_{\mathrm{L}}, \mathrm{L} / \mathrm{mg}$ & 0,03 \\
\hline $\mathrm{R}_{\mathrm{L}}$ & 0,88 \\
\hline Ortalama rölatif hata (ARE) & 1,40 \\
\hline Standart sapma, (NSD) & 0,26 \\
\hline
\end{tabular}

Çizelge 4'de hesaplanan değerler incelendiği zaman DKK'nun tek tabaka fosfor tutma kapasitesinin $24,51 \mathrm{mg} / \mathrm{g}$ olduğu ve adsorpsiyonun geri dönüşümlü $\left(\mathrm{R}_{\mathrm{L}}=0,88\right)$ olduğu anlaşılmaktadır. Zhang ve arkadaşları [13], sentezlemiş oldukları malzeme (CSA) ile üç farklı sıcaklık değerinde $\left(30{ }^{\circ} \mathrm{C}, 45{ }^{\circ} \mathrm{C}\right.$ ve $\left.60{ }^{\circ} \mathrm{C}\right)$ fosfor giderim verileri elde etmiş ve elde ettikleri veriler ile yapmış oldukları adsorsiyon izotermi uygulamasinda izotermin Langmuir izotermine uyduğu, $\mathrm{q}_{\mathrm{m}}$ ve $\mathrm{K}_{\mathrm{L}}$ değerlerinin ise sirası ile $3,81 \mathrm{mg} / \mathrm{g}$ ve $0,82 \mathrm{~L} / \mathrm{mg}$ $\left(30{ }^{\circ} \mathrm{C}\right), 4,23 \mathrm{mg} / \mathrm{g}$ ve $0,64 \mathrm{~L} / \mathrm{mg}\left(45^{\circ} \mathrm{C}\right)$ ve $4,23 \mathrm{mg} / \mathrm{g}$ ve $0,51 \mathrm{~L} / \mathrm{mg}\left(60{ }^{\circ} \mathrm{C}\right)$ olduğunu bildirmişlerdir. Koh ve arkadaşları [3], sentezlemiş olduklar1 gadolinium-1,4-benzenedicarboxylate ile fosfor giderimi çalışmışlardır. Yapmış oldukları izoterm çalışmasında ise adsorpsiyonun Langmuir izotermi ile açıklandığını, $\mathrm{q}_{\mathrm{m}}$ değerinin $166,91 \mathrm{mg} / \mathrm{g}$ ve $\mathrm{K}_{\mathrm{L}}$ değerlerinin ise $11 \mathrm{~L} / \mathrm{mg}$ olduğunu tespit etmişledir. Yang ve arkadaşları [21], kömür ve cüruf ile fosfor giderimi çalışarak yaptıkları izoterm analizinde adsorpsiyonun Langmuir izotermine uyduğunu tespit etmişlerdir. İzoterm sabitlerinden olan $\mathrm{q}_{\mathrm{m}}$ değerlerini kömür ve cüruf için sırası ile $0,398 \mathrm{mg} \mathrm{P} / \mathrm{g}, 2,417 \mathrm{mg} \mathrm{P} / \mathrm{L}$ olarak ve $\mathrm{K}_{\mathrm{L}}$ değerlerini ise sirası ile $0,113 \mathrm{~L} \mathrm{mg} \mathrm{P}$ ve $0,266 \mathrm{~L} / \mathrm{mg}$ P olarak tespit etmişlerdir. 


\section{SONUÇLAR VE ÖNERILER}

$\mathrm{Bu}$ çalışmada ticari olarak satışı bulunan aktif karbon materyali demir ile kaplanarak yeni bir malzeme sentezlenmiştir. Sentezlenmiş olan demir kaplanmış aktif karbon kullanılarak fosfor giderimi araştırılmış ve \%95,2 fosfor giderimi tespit edilmiştir. Demir modifiyeli karbonun fosfor tutma kapasitesi ise 4,26 mg $\mathrm{PO}_{4}{ }^{3-} / \mathrm{g}$ DKK belirlenmiştir. Analiz sonuçlarının adsorpsiyon izoterm modellerine veri olarak kullanılması ile birlikte adsorpsiyonun Langmuir Tip 2 izotermine uyduğu $\left(\mathrm{q}_{\mathrm{m}}=24,51 \mathrm{mg} / \mathrm{g}\right.$ ve $\left.\mathrm{K}_{\mathrm{L}}=0,03 \mathrm{~L} / \mathrm{mg}\right)$ tespit edilmiştir.

Aktif karbonun maliyetinin düşük olması sebebiyle demir modifiyeli karbonun sentezinin uygun şartlar sağlandığı takdirde ekonomik anlamda uygulanabilir olduğu bu çalışmada kanıtlanmıştır. Bir sonraki aşamada ise sentezlenmiş olan malzemenin fosfor tutma kapasitesinin arttırılması, uygun kolon proseslerinde kullanılabilirliği ve Dünya'da kaynakları sınırlı olan fosforun geri kazanımı ile ilgili çalışmalar yapılarak literatüre bu yönde çalışmaların eklenmesi mümkün görülmektedir.

\section{KAYNAKLAR}

1. Choi, J., Lee, S., Park, K., Lee, K., Kim, D., Lee, S., 2011. Investigation of Phosphorous Removal From Wastewater Through Ion Exchange of Mesostructure Based on İnorganic Material. Desalination, 266, 281-285.

2. Novillo, C., Guaya, D., Allen-Perkins Avendaňo, A., Armijos, C., Cortina, J.L., Cota, I., 2014. Evaluation of Phosphate Removal Capacity of $\mathrm{Mg} / \mathrm{Al}$ Layered Double Hydroxides from Aqueos Solutions. Fuel, 138, 72-79.

3. Koh, K.Y., Wang, C., Chen, J.P, 2019. A New Adsorbent of GAdolinium-1,4benzenedicarboxylate Composite for Better Phosphorous Removal in Aqueous Solutions. Journal of Colloidal and Interface Science, 543, 343-351.

4. Das, J., Patra, B.S., Baliarsingh, N., Parida, KM., 2006. Adsorption of Phosphate by
Layered Double Hydroxides in Aqueous Solutions. Applied Clay Science, 32, 252-260.

5. Föllmi, K.B., 1996. The Phosphorus Cycle, Phosphogenesis and Marine Phosphate-rich Deposits. Earth Science Reviews, 40, 55-124.

6. Karageorgiu, K., Paschalis, M., Anastassakis, G.N., 2007. Removal of PHOSPHATE SPECIES from Solution by Adsorption onto Calcite Used as Natural Adsorbent. Journal of Hazardous Materials, 139, 447-452.

7. Nur, T., Johir, M.A.H., Loganathan, P., Nguyen, T., Vigneswaran, S., Kandasamy, J., 2014. Phosphate removal from Water Using and Iron Oxide Impregnated Strong Base Anion Exhange Resin. Journal of Industrial and Engineering Chemistry. 20, 1301-1307.

8. Caravelli, A.H., Contreras, E.M., Zaritzky, N.E., 2010. Phosphorous Removal in Batch Systems Using Ferric Chloride in the Presence of Activated Sludges. Journal of Hazardous Materials, 177, 199-208.

9. Kpannieu, D.E., Mallet, M., Coulibaly, L., 2019. Phosphate Removal from Water by Naturally Occurring Shale, Sandstone and Laterite: Tehe Role of Iron Oxides and of Soluble Species, 351, 37-47.

10. Yin, H., Yun, Y., Zhang, Y., Fan, C., 2011. Phosphate Removal From Wastewaters by a Naturally Occurring, Calcium-rich Sepiolite. Journal of Hazardous Materials, 198, 362-369.

11. Kuzawa, K., Jung, Y., Kiso, Y., Yamada, T., Nagai, M., Lee, T., 2006. Phosphate Removal and Recovery with a Synthetic Hydrotalcite as an Adsorbent. Chemosphere, 62, 45-52.

12. Zhong-Liang, S., Fu-Mei, L., Shu-Hua, Y., 2011. Adsorptive Removal of Phosphate from Aqueous Solutions Using Activated Carbon Loaded with $\mathrm{Fe}(\mathrm{III})$ Oxide. New Carbon Material, 26(4), 299-306.

13. Zhang, L., Liu, J., Guo, X., 2018. Investigation on Mechanism of Phosphate Removal on Carbonized Sludge Adsorbent, Journal of Environmental Sciences, 64, 335-344.

14. Yeşiltaş, H.K., Yilmaz, T., 2018. Çift Katmanlı Hidroksitler ile Fosfor Gideriminin Araştırılması, Ç.Ü. Fen ve Mühendislik Bilimleri Dergisi, 35-8, 106-115.

15. Gisi, S.D., Lofrano, G., Grassi, M., Notarnicola, M., 2016. Characteristics and 
Adsorption Capacities of Low-cost Sorbent for Wastewater Treatment: A Review, Sustainable Materials and Technologies, 9, 10-40.

16. Bottani, E.J., Tascón, J.M.D., 2008. Adsorption by Carbons, Elsevier Science, 776.

17. Rice, E.W., Baird, R.B., Eaton, A.D., Clesceri, LS., 2012. Standard Methods for the Examination of Water and Wastewater, Washington, 1496.

18. Behnamfard, A., Salarirad, M.M., 2009. Equilibrium and Kinetic Studies on Free Cyanide Adsorption from Aqueous Solution by Activated Carbon. Journal of Hazardous Materials, 170, 127-133.

19. Barca, C., Gérente, C., Meyer, D., Chazarenc, F., Andrés, Y., 2012. Phosphate Removal from Synthetic and Real Wastewater Using Steel Slags Produced in Europe, Water Research, 40, 2376-2384.

20. Krishna, K.C.B., Niaz, M.R., Sarker, D.C., Jansen, T., 2017. Phosphorous Removal from Aqueous Solution Can Be Enhanced Through the Calcination of Lime Sludge, Journal of Encironmental Management, 200, 359-365.

21. Yang, J., Wang, S., Lu, Z., Yang, J., Lou, S., 2009. Converter Slag-coal Cinder Columns fort he Removal of Phosphorous and Other Pollutants, Journal of Hazardous Materials, 168, 331-337. 